\title{
Semiconductive Properties of Anodic Niobium Oxides
}

\author{
A.I. de Sá, ${ }^{a, *}$ C.M. Rangel, ${ }^{a}$ P. Skeldon, ${ }^{b}$ G.E. Thompson ${ }^{b}$ \\ ${ }^{a}$ DMTP/Electroquímica de Materiais, Instituto Nacional de Engenharia Tecnologia \\ e Inovação, Paço do Lumiar, 22, 1649-038 Lisboa-Portugal \\ ${ }^{b}$ Corrosion and Protection Centre, School of Materials, The University of Manchester, \\ P.O. Box 88, Manchester M60 1QD, UK
}

Received 30 November 2005; accepted 16 April 2006

\begin{abstract}
The semiconductive properties of anodic niobium oxides formed at constant potential and constant current density to different final voltages have been examined by MottSchottky analysis.

Thin anodic oxides were formed on sputtered niobium specimens at constant potential in the range of 2.5 to $10 \mathrm{~V}_{\mathrm{Ag} / \mathrm{AgCl}}$ in a borate buffer solution. Thicker oxides were formed, also on sputtered niobium specimens, at a constant current density of $5 \mathrm{~mA} \mathrm{~cm}^{-}$ 2 in $0.1 \mathrm{M}$ ammonium pentaborate solution to final voltages of 10,50 and $100 \mathrm{~V}$.

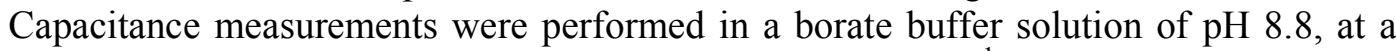
frequency range of 200 to $2000 \mathrm{~Hz}$, at a sweep rate of $5 \mathrm{mV} \mathrm{s}^{-1}$ from +2.5 to $-1 \mathrm{~V}_{\mathrm{Ag} / \mathrm{AgCl}}$. The results obtained show n-type semiconductor behaviour with a carrier density in the range of $8 \times 10^{18}-6 \times 10^{19} \mathrm{~cm}^{-3}$ on films formed to $10 \mathrm{~V}$. Thicker films showed lower carrier densities in the range of $1 \times 10^{18}-2 \times 10^{18} \mathrm{~cm}^{-3}$ with a calculated charge depletion layer of 33-36 nm.
\end{abstract}

Keywords: niobium oxides, anodic oxides, Mott-Schottky behaviour.

\section{Introduction}

Niobium, together with aluminium and tantalum, belongs to the so-called group of valve-metals. On these materials, an oxide of increasing thickness is formed when a current is passed through a cell containing a suitable electrolyte. The process is possible because the resultant oxide has low electronic conductivity and, when an appropriately high electrical field is applied across the metal/oxide/electrolyte system, ionic transport proceeds [1,2]. The valve-metal oxides can have different ionic conductivities and local structures and they have

\footnotetext{
* Corresponding author. E-mail address: Ana.Sa@ineti.pt
} 
been extensively used as protective coatings against corrosion or as dielectric materials for the electronic industry $[3,4]$.

Niobium oxide is now starting to replace tantalum oxide as a dielectric material in specific capacitors for the electronic industry. However, there are other potential applications for this oxide, including optic-electronic screens and solar energy conversion cells, since the oxide shows electrochromic and photoelectrochemical properties [5,6].

Anodic niobia is usually classified as an n-type semiconductor due to the associated value of the band-gap energy (3.4- 5.3 eV) [7], but factors such as stoichiometry, incorporated foreign species and crystallinity can have an influence on the behaviour of a particular oxide [8,9].

In this paper the semiconducting properties of anodic niobium oxides, formed at constant potential and constant current density with different resultant thicknesses, are analysed from their Mott-Schottky behaviour. The results obtained show n-type semiconductor properties with a carrier density in the range of $8 \times 10^{18}-6 \times 10^{19} \mathrm{~cm}^{-3}$ on films formed to $10 \mathrm{~V}$. For films of increased thickness reduced carrier densities, in the range of $1 \times 10^{18}-2 \times 10^{18} \mathrm{~cm}^{-3}$, are calculated.

\section{Experimental}

Niobium specimens were deposited by magnetron sputtering using an Atom Tech Ltd system with a target of niobium (99.9\%). Sputtering was performed in $5 \times$ $10^{-1} \mathrm{~Pa}$ argon after previous evacuation to $5 \times 10^{-5} \mathrm{~Pa}$. The substrates consisted of high purity aluminium sheet that had been electropolished for $180 \mathrm{~s}$ at $20 \mathrm{~V}$ in a solution of ethanol and perchloric acid ( $4: 1$ by vol.) at $283 \mathrm{~K}$, then anodised to $150 \mathrm{~V}$ at $5 \mathrm{~mA} \mathrm{~cm}^{-2}$ in $0.1 \mathrm{M}$ ammonium pentaborate solution at $293 \mathrm{~K}$ to provide a flat surface for deposition.

Niobium specimens of working area $2 \mathrm{~cm}^{2}$, were anodized at $5 \mathrm{~mA} \mathrm{~cm}$ to 10,50 and $100 \mathrm{~V}$, in $0.1 \mathrm{M}$ ammonium pentaborate at $293 \mathrm{~K}$, with recording of the resultant voltage-time behaviours. Selected anodic oxides were also formed on sputtered niobium specimens at constant potential in the range of 2.5 to 10 $\mathrm{V}_{\mathrm{Ag} / \mathrm{AgCl}}$ in a borate buffer solution $\left(0.15 \mathrm{M} \mathrm{H}_{3} \mathrm{BO}_{3}+0.075 \mathrm{M} \mathrm{Na}_{2} \mathrm{~B}_{4} \mathrm{O}_{7}\right)$ of $\mathrm{pH}$ 8.8. The potential was applied for 10 minutes.

Capacitance measurements were performed in the borate buffer solution in the frequency range of 200 to $2000 \mathrm{~Hz}$, at a sweep rate of $5 \mathrm{mVs}^{-1}$ from +2.5 to -1 $\mathrm{V}_{\mathrm{Ag} / \mathrm{AgCl}}$, a frequency analyser, model 1250 (Solartron) coupled to an electrochemical interface, model 1280 also from Solartron, controlled by a PC via Zplot software. A three-electrode electrochemical cell was used with an $\mathrm{Ag} / \mathrm{AgCl}$ reference electrode and a platinum wire $\left(10 \mathrm{~cm}^{2}\right.$ surface area) as the auxiliary electrode.

\section{Results}

The anodising of niobium under the experimental conditions has been examined elsewhere, showing that a linear plot voltage-time response is obtained due to the 
formation of anodic niobia. RBS analysis of the oxide showed a uniform composition of $\mathrm{Nb}_{2} \mathrm{O}_{5}$ within an experimental accuracy of $\pm 5 \%$ [10].

The semiconductor-oxide/electrolyte interface has a characteristic behaviour because a space-charge region can be formed as a result of the electrochemical equilibrium achieved. For an n-type semiconductor a charge depleted layer is usually formed, with a capacitance $\left(\mathrm{C}_{\mathrm{SC}}\right)$ that is related to the applied voltage $(\mathrm{U})$ according to the Mott-Schottky equation:

$$
\frac{1}{C_{S C}^{2}}=\left(\frac{2}{\varepsilon_{o} \varepsilon_{r} e N_{D}}\right)\left(U-U_{f b}-\frac{k T}{e}\right)
$$

where $\varepsilon_{\mathrm{r}}$ is the relative dielectric constant of the oxide $\varepsilon_{\mathrm{o}}$ is the vacuum permittivity, e is the electron charge, $\mathrm{N}_{\mathrm{D}}$ is the carrier density, $\mathrm{U}$ is the applied potential, $\mathrm{U}_{\mathrm{fb}}$ is the flat band potential, $\mathrm{k}$ is the Boltzmann constant and $\mathrm{T}$ is the absolute temperature. The equation is only obeyed in a potential range near the flat-band potential [11]. The value of $\mathrm{N}_{\mathrm{D}}$ is obtained from the slope of the plot of $\mathrm{C}^{-2}$ against $\mathrm{U}$ and corresponds to the delocalised electrons located in the conduction band. Typical values are in the range of $10^{16}$ to $10^{18} \mathrm{~cm}^{-3}$, which is about six orders of magnitude lower than the delocalised electrons in metals [12].
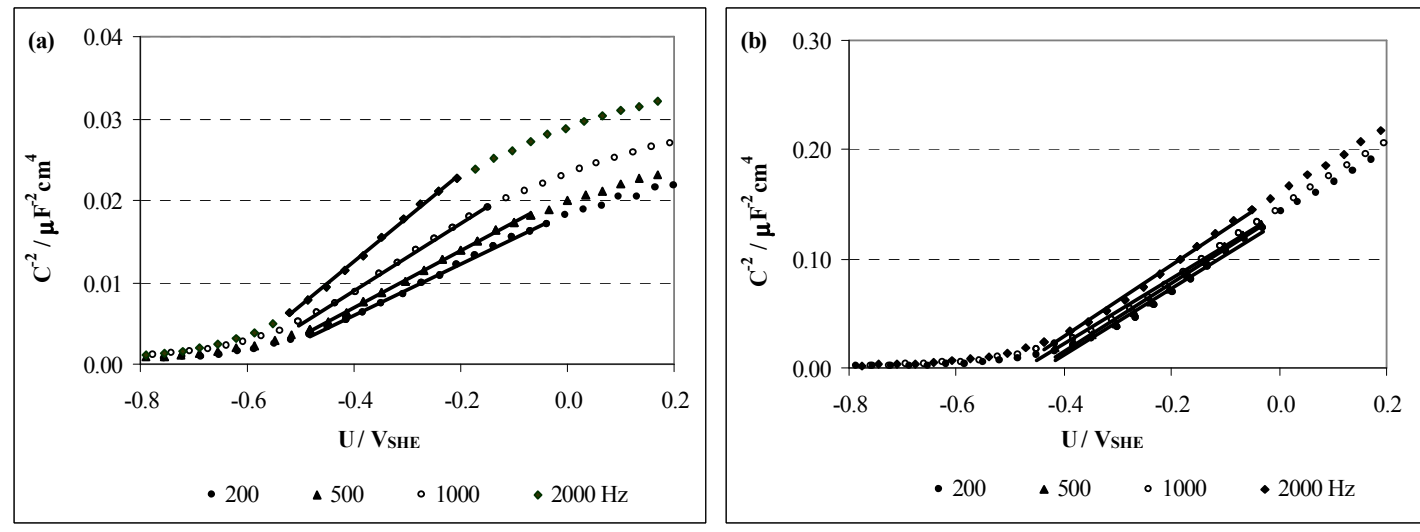

Figure 1. Mott-Schottky plot for anodic niobia formed at constant potential of (a) $2.5 \mathrm{~V}$ and (b) $10 \mathrm{~V}$ in the borate buffer solution.

The flat band potential can be determined only if the capacitance values are lower than the double layer capacitance (usually in the range 10 to $100 \mu \mathrm{F} \mathrm{cm}{ }^{-2}$ ) and assuming that there are no other contributions to the capacitance values [11]. The results, independently of the oxide thickness and oxide forming technique, show Mott-Schottky behaviour in the potential range of -0.2 to $-0.6 \mathrm{~V}_{\text {SHE }}$ (Figs. 1 to 3). The plots at different frequencies in the range 200-2000 Hz appear to converge to a common potential value as expected [12]. From this value of potential, the flat band potential is calculated according to $\left(\mathrm{U}_{\mathrm{fb}}=\mathrm{U}-\mathrm{kT} / \mathrm{e}\right)$. The carrier density values obtained are in the range $10^{18}-10^{19} \mathrm{~cm}^{-3}$ showing that the "doping level" is not too high (Tables 1 and 2). The oxides formed to $10 \mathrm{~V}$ at constant potential, show a decrease of the carrier density with increase of oxide thickness. The values calculated for an anodising voltage of $10 \mathrm{~V}$ are considered 
similar for both anodising methods, suggesting that the oxide thickness is the determining factor for the donor concentration variation in this potential range (Tables 1 and 2).

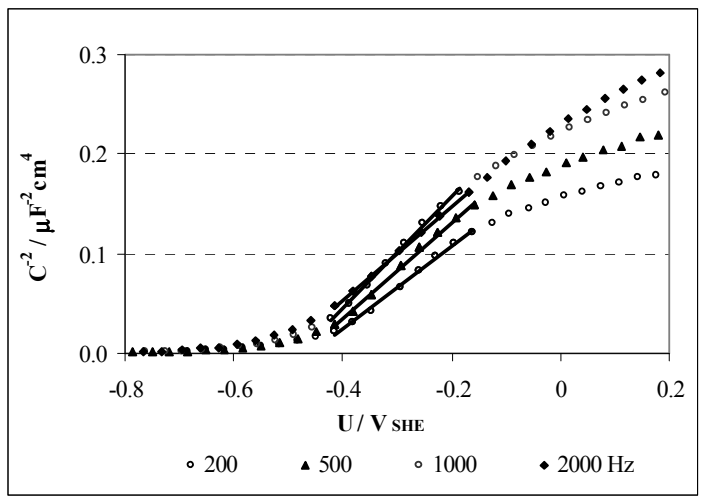

Figure 2. Mott-Schottky plot for anodic niobia formed to $10 \mathrm{~V}$, at constant current density of $5 \mathrm{~mA} \mathrm{~cm}^{-2}$ in $0.1 \mathrm{M}$ ammonium pentaborate solution.
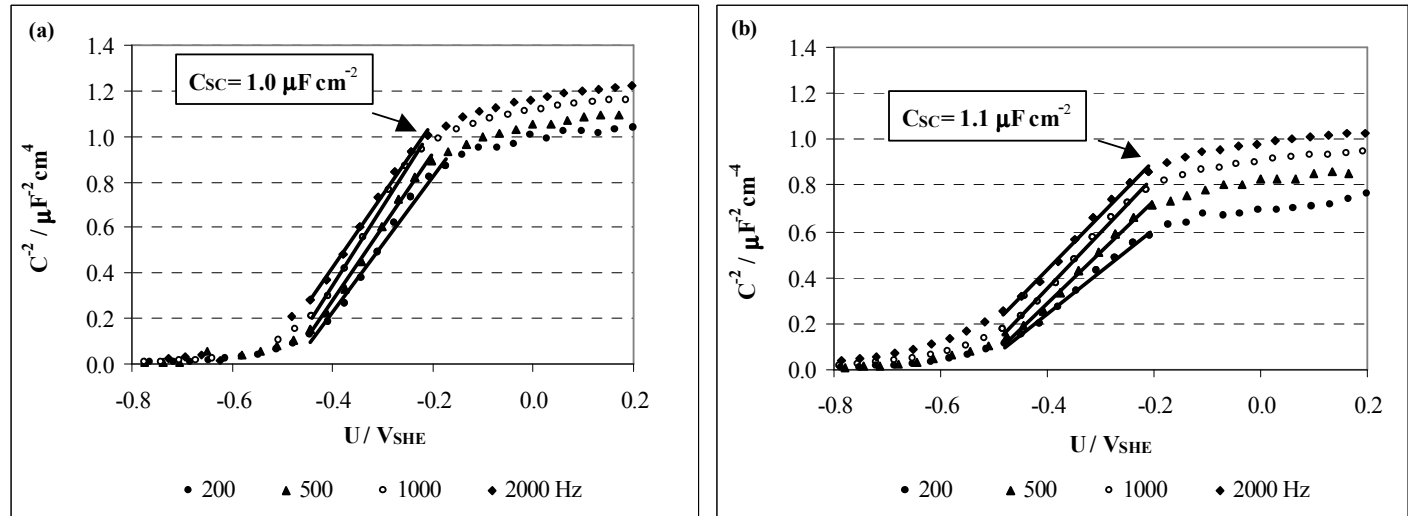

Figure 3. Mott-Schottky plot for anodic niobia formed to (a) 50 and (b) $100 \mathrm{~V}$ at constant current density of $5 \mathrm{~mA} \mathrm{~cm}^{-2}$ in $0.1 \mathrm{M}$ ammonium pentaborate solution.

The flat band potential is only calculated for films formed to $50 \mathrm{~V}$ and $100 \mathrm{~V}$, where the capacitance range is closer or lower than $1 \mu \mathrm{F} \mathrm{cm}$, to assure that the double layer is not affecting the values. The values of flat band potential are, respectively, -0.541 and $-0.611 \mathrm{~V}_{\mathrm{SHE}}$, in agreement with Biaggio et al. [13], but significantly more negative than values reported by other authors $[7,9,14]$.

Table 1. Mott-Schottky results obtained at $2000 \mathrm{~Hz}$ of the carrier density of the anodic niobia formed at constant potential.

\begin{tabular}{cc}
\hline Anodising voltage / V & $\mathrm{N}_{\mathrm{D}} / \mathrm{cm}^{-3}$ \\
\hline 2.5 & $6.30 \times 10^{19}$ \\
5.0 & $2.75 \times 10^{19}$ \\
7.5 & $1.70 \times 10^{19}$ \\
10 & $1.06 \times 10^{19}$ \\
\hline
\end{tabular}


Table 2. Mott-Schottky results obtained at $2000 \mathrm{~Hz}$ of the carrier density and flat band potential of the anodic niobia formed at constant current density.

\begin{tabular}{ccc}
\hline $\begin{array}{c}\text { Anodising } \\
\text { voltage } / \mathrm{V}\end{array}$ & $\mathrm{N}_{\mathrm{D}} / \mathrm{cm}^{-3}$ & $\mathrm{E}_{\mathrm{fb}}\left(\mathrm{V}_{\mathrm{SHE}}\right)$ \\
\hline 10 & $7.34 \times 10^{18}$ & --- \\
50 & $1.11 \times 10^{18}$ & -0.566 \\
100 & $1.45 \times 10^{18}$ & -0.610 \\
\hline
\end{tabular}

\section{Discussion}

The experimental results obtained are consistent, certainly associated with the clean and flat sputtered metal surfaces used for anodising, avoiding roughness and foreign surface treatment species that can influence the semiconductor properties.

A power relation $\left(y=a x^{b}\right)$ has been observed for the variation of the carrier density with anodising potential for $\mathrm{WO}_{3}[15,16] \mathrm{TiO}_{2}[17]$ as well as for anodic niobia [9]. The experimental results of this work confirm this dependence, assuming that only the final voltage is the determining factor (Fig. 4).

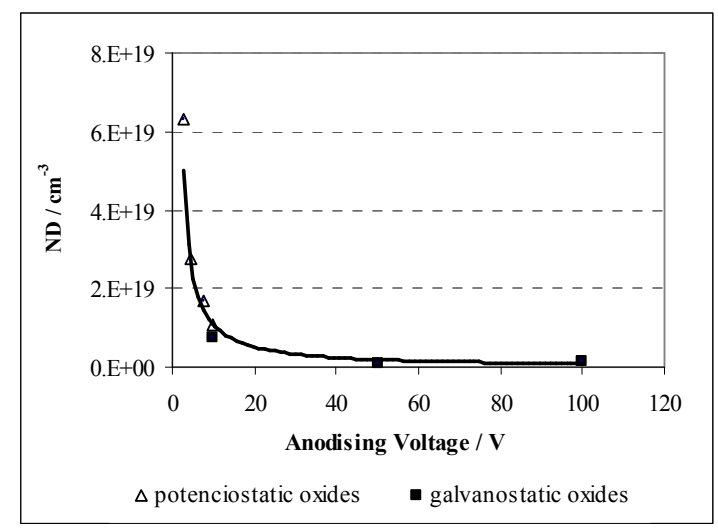

Figure 4. Dependence of carrier density on final anodising voltage for the anodic niobium oxides obtained at constant potential and constant current density.

The Mott-Schottky plots obtained at $2000 \mathrm{~Hz}$ for the oxides formed to 50 and $100 \mathrm{~V}$, show an inflection point close to the same values of capacitance and potential (Fig.3). At increased anodic potential, the capacitance still changes with potential, but at a lower rate. A possible interpretation for this feature is to consider that a complete depleted charge carrier layer is achieved at that potential. Modestov et al. have found a similar behaviour on anodic niobia grown to voltages as high as $200 \mathrm{~V}$ [18]. The system at this point can be represented by a plane-plate capacitor:

$$
C_{S C}=\frac{\varepsilon_{r} \varepsilon_{o}}{L_{S C}}
$$


where $-\mathrm{L}_{\mathrm{SC}^{-}}$is the thickness of the depletion layer. The layer thicknesses calculated assuming a conversion factor of $2.3 \mathrm{~nm} / \mathrm{V}$ [19] have the values of 33 and $36 \mathrm{~nm}$ at 100 and $50 \mathrm{~V}$, respectively. The values seem very reasonable as the depletion layer can extend from 10 to $1000 \mathrm{~nm}$. The thickness of the depleted layer corresponds to an anodising voltage of $15.2 \mathrm{~V}$. This value is close to the turning point shown by the power relation fitted to the experimental data (Fig. 4). This suggests that, whenever the depletion layer is thinner than the total oxide layer, the semiconductor/electrolyte interface exhibits a nearly constant carrier density, assuming that the oxide has a constant composition. When the charge depletion layer thickness is similar to the total oxide thickness, the interface metal/oxide has influence on the carrier density (Fig. 5). A possible reason for this effect may be the presence of a non-stoichiometric oxide close to the metal surface and also to the possibility of a decreasing thickness of this thin oxide layer with anodising potential and time.

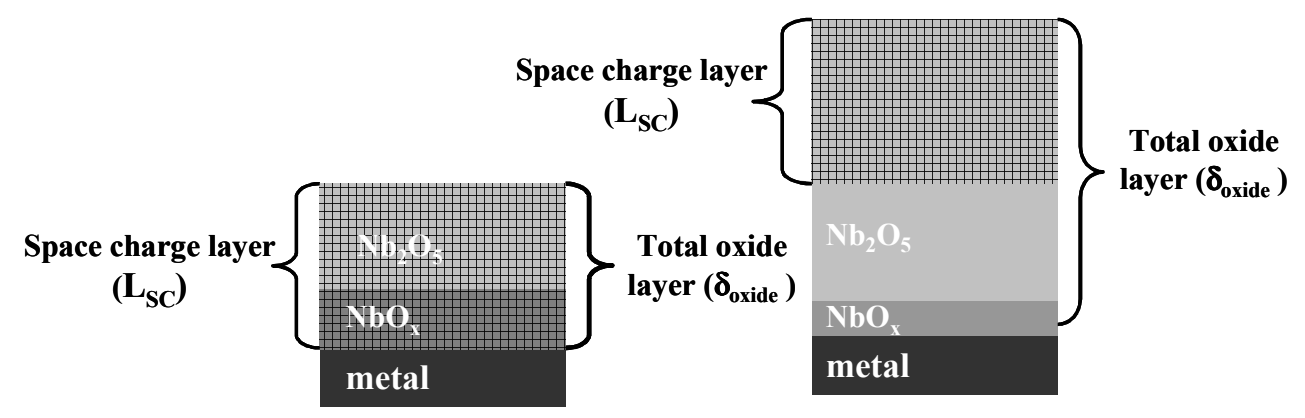
a) $\mathbf{L}_{\mathrm{SC}}=\boldsymbol{\delta}_{\text {oxide }}$
b) $\mathrm{L}_{\mathrm{SC}}<\delta_{\text {oxide }}$
$\mathbf{N}_{\mathrm{D}}=\mathbf{f}\left(\boldsymbol{\delta}_{\mathrm{ox}}\right)$
$N_{D}=$ constant

Figure 5. Schematic diagram of the system metal/semiconductor oxide/electrolyte for a charge depletion layer $\left(\mathrm{L}_{\mathrm{SC}}\right)$ formed with a thickness similar to (a) and lower than (b) the total thickness of the oxide layer $\left(\delta_{\text {ox }}\right)$.

\section{Conclusions}

- Anodic niobium oxides formed on sputtered niobium show semiconductor behaviour when examined by Mott-Schottky plots.

- N-type semiconductor behaviour is revealed with a carrier density in the range $8 \times 10^{18}-6 \times 10^{19} \mathrm{~cm}^{-3}$ for films formed to $10 \mathrm{~V}$. Films of increased thickness show reduced carrier densities in the range $1 \times 10^{18}-2 \times 10^{18} \mathrm{~cm}^{-3}$.

- Anodic oxides formed to voltages of 50 and $100 \mathrm{~V}$ show an almost constant carrier density, associated with a charge depletion layer that is thinner than the total oxide thickness. 


\section{References}

1. L. Young, in Anodic Oxide Films, Academic Press, London/New York, 1961. p.13.

2. G.E. Thompson, Thin Solid Films 297 (1997) 192-201.

3. S. Wernick, R. Pinner, P.G. Sheashy, in The Surface Treatment and Finishing of Aluminium and its Alloys, ASM International Eds, $5^{\text {th }}$ edition, Ohio, USA 1987. p. 289.

4. P.J. Harrop, D.S. Campbell, in Handbook of Thin Film Technology", I.I. Maissel and R. Gland Eds, Mc. Graw-Hill. New York, 1970. p.16.

5. A. Vaskevich, M. Rosenvlum, E. Gileadi, J. Electrochem. Soc. 142 (1995) 1501-1508.

6. M. Schmitt, M.A. Aegerter, Electrochim. Acta 46 (2001) 2105-2513.

7. J.W. Schultze, M.M. Lohrengel, Electrochim. Acta 45 (2000) 2499-2513.

8. A.K. Vijh, in Oxides and Oxide Films, Marcel Dekker, Eds., New York, 1973. p. 150 .

9. K.E. Heusler, M. Shulze, Electrochim. Acta 20 (1975) 237-244.

10. A.I. de Sá, C.M. Rangel, P. Skeldon, G.E. Thompsom, Key Engineering Materials 230 (2002) 44-47.

11. N. Micaroni, C.N. Polo da Fonseca, F. Decker, M-A De Paoli, Solar Energy Materials \& Solar Cells 60 (2000) 27-41.

12. W.P. Gomes, D. Vanmaekelbergh, Electrochim. Acta 41 (1996) 967-973.

13. S.R. Biaggio, N. Bocchi, R.C. Rocha-Filho, F.E. Varela, J. Braz. Chem. Soc. 8 (1997) 615-620.

14. F. Di Quarto, S. Piazza, S. Sunseri, Electrochim. Acta 35 (1990) 99-107.

15. F. Di Quarto, A. Di Paola, C. Sunseri, Electrochim. Acta 26, (1981) 11771184.

16. S.R. Biaggio, R.C. Rocha-Filho, J.R. Vilche, F.E. Varela, L.M. Gassa, Electrochim. Acta 42 (1997) 1751-1758.

17. N. Ibris, Russian Journal of Electrochemistry 39 (2003) 476-479.

18. A.D. Modestov, A.D. Dadydov, J. Electroanal. Chemistry 460 (1999) 214225.

19. J.P.S. Pringle, Electrochim. Acta 25 (1980) 1423-1437. 